\title{
UTILIZACION DE DIETAS PRACTICAS CON DIFERENTES NIVELES DE AMINOACIDOS AZUFRADOS TOTALES PARA EL CRECIMIENTO DE GAMITANA (Colossoma macropopum), PISCES CHARACIDAE
}

\author{
Gutiérrez Alva, Walter* \\ Zaldivar Rodríguez, J avier* \\ Rebaza Alfaro, Mariano**
}

\section{RESUMEN}

Con la finalidad de estimar en dietas prácticas el nivel mínimo de proteína y el suministro suficiente de aminoácidos azufrados, capaces de satisfacer las demandas de crecimiento y mantener un estado fisiológico normal de la gamitana, se formularon cuatro dietas prácticas isocalóricas, diseñadas para contener $0.90,1.02$, y $1.32 \%$ de metionina + cistina, como porcentaje de la dieta. Se utilizaron como fuentes de proteína harina de pescado (anchoveta) y torta de soya y como fuentes de carbohidratos maíz y subproducto de trigo. Los resultados obtenidos indican que la dieta con $25.94 \%$ de proteína, $2700 \mathrm{kcal} / \mathrm{kg}$ de alimento, $1.02 \%$ de metionina + cistina en la dieta y una relación Energía Digestible/Proteína de $10.41 \mathrm{kcal} / \mathrm{g}$ de proteína fue la más eficientemente utilizada $(P<0.01)$ en términos de ganancia de peso y proteína.

\section{ABSTRACT}

With the purpose of estimating in practical diets the minimum level of protein and the adequate supply of sulphuring aminoacids to obtain an optimum increase in growth and normal physiological state of the gamitana (Colossoma macropomum), four isocaloric practical diets were formulated with $0.90,1.02,1.20$ and $1.32 \%$ of methionine plus cystine as a percentage of the practical diets. Fish meal (anchovy) and soybean meal were used as protein source and corn meal and wheat bran as carbohydrate source. These results indicate that a diet containing $25.4 \%$ crude protein, $2700 \mathrm{kcal} / \mathrm{kg}$ diet, $1.02 \%$ of

Centro de Investigación IVITA de la Universidad Nacional Mayor de San Marcos. Fax 353064. Lima.

** Centro Regional de Investigación de Ucayali del Instituto de Investigaciones de la Amazonia

Peruana. Fax 573732, Pucallpa. 
methionine plus cystine as porcentage of the diet and Digestible Energy to Dietary Protein ratio of $10.41 \mathrm{kcal} / \mathrm{g}$ protein, appeared to be utilized more efficiently $(P<0.01)$ in terms of weight gain and percentage of retained protein.

Palabras claves: Nutrición, Gamitana, Aminoácidos azufrados.

\section{INTRODUCCION}

En los peces, la cuantificación de los requerimientos de proteína y aminoácidos esenciales tienen una especial trascendencia. Desde el punto de vista práctico, la proteína, al ser requerida en altas proporciones por la mayoría de peces cultivables Cowey (1974), Millikin (1982), crean dependencia exterior en muchos países y su alto precio en el mercado encarece considerablemente la formulación de dietas comerciales y condiciona, en muchas ocasiones la rentabilidad de la producción piscícola. En consecuencia, uno de los principales objetivos de la nutrición de peces es obtener la máxima incorporación de la proteína de la dieta a las estructuras implicadas en el crecimiento corporal. Para ello, se debe establecer el mínimo nivel de proteína dietaria que asegure la presencia, en los lugares de síntesis proteica, de un patrón específico de aminoácidos en cantidades adecuadas. Interesa un mayor destino de la proteína dietaria hacia crecimiento, minimizando al máximo el costo proteico del mantenimiento que incluye, en lineas generales, síntesis de proteínas funcionales, gluconeogénesis y energía. La síntesis de proteínas funcionales y el mantenimiento de procesos biológicos suponen un gasto obligatorio, que no pueden modificarse sin consecuencias negativas. Sin embargo, el destino gluconeogénicco y energético, hasta cierto punto, puede y debe ser controlado.

Un aspecto que debe evaluarse y tenerse en cuenta cuando se trata de ajustar la proteína de la dieta a los requerimientos de aminoácidos esenciales es la capacidad de algunos de ellos de ser sustituidos por aminoácidos no esenciales, lo que permite a nivel práctico no desestimar una fuente proteica cuando su contenido en algunos de aquellos aminoácidos, con posibilidad de ser sustituidos parcialmente por no esenciales, está por debajo de los requerimientos establecidos. Este es el caso de la pareja de aminoácidos azufrados metionina y cistina. La interacción metionina - cistina tiene una especial importancia debido a que la metionina es uno es uno de los aminoácidos más limitantes en la dieta de los peces, especialmente cuando se emplean fuentes de origen vegetal Ketola (1982); Poston et al. (1977); Rumsey et al. (1983). 
Normalmente en la formulación de dietas comerciales, la atención es puesta en cubrir los requerimientos de los aminoácidos azufrados, ya que un nivel adecuado de éstos implica niveles adecuados de los otros aminoácidos esenciales. Se ha demostrado, para algunas especies, que la presencia de cistina en la dieta reduce las concentraciones de metionina necesarias para máximo crecimiento. La sustitución de metionina por cistina, en términos equimolares de azufre, es de hasta $60 \%$ en el pez gato del canal Harding et al. (1977), de hasta $50 \%$ en la trucha arco iris Kim et al. (1984) y de hasta $50 \%$ en la tilapia del nilo Santiago y Lovell (1988).

Las investigaciones sobre requerimientos de proteína en gamitana (Colossoma macropomum) han sido escasas y dispersas y se han encontrado requerimientos que van desde $18 \%$ hasta $50 \%$ de proteína. Macedo (1979), encontró que el nivel óptimo de proteína cruda de la dieta fue de alrededor de 23\%. Carneiro (1981), encontró que la mejor digestión de la proteína fue alcanzada cuando las dietas fluctuaron entre $18 \%$ y $22 \%$ de proteína. En experimentos utilizando varias dietas con $30 \%$, se encontró que la mejor tasa de crecimiento se alcanzó cuando la proporción de proteína de origen vegetal fue más grande (Werder y Saint Paul 1978). El CEPTA del Brasil, publicó en 1987 una síntesis de los trabajos realizados con las especies del género Colossoma, entre éstos hay algunos sobre nutrición que demuestran la potencialidad de estos peces cuando fueron alimentados con dietas comerciales para pollos, cerdos y carpas. También se encontró que el pacú (Colossoma mitrei ), creció adecuadamente con niveles de $25 \%$ de proteína dietaria y 2600 kcal de energía digestible, cuando se le alimentó con diferentes proporciones de proteína de origen animal y vegetal. Eckmann (1987), usando harina de sangre como fuente complementaria de proteína para dietas con $25 \%$ y $37 \%$, alcanzó Tasas Específicas de Crecimiento (TEC) entre $0.8 \%$ y $2.1 \% /$ día. Darmont y Salaya(1984), utilizando dietas con $50 \%$ de proteína obtuvieron una TEC de 1.28\%/día. Gutiérrez (1988), evaluó dos niveles de proteína(25\% y 35\%), utilizando harina de pescado y torta de soya como fuentes de proteína encontrando una mejor respuesta con $25 \%$ de proteína dietaria $(0.90 \%$ de metionina + cistina como porcentaje de la dieta). Merola y Cantelmo (1987), no encontraron diferencias significativas entre las ganancias de peso, TEC y eficiencia de conversión alimenticia, cuando alimentaron a la gamitana con dietas que contenían niveles de 30\%, 35\% y 40\% de proteína.

El propósito del estudio fue evaluar en dietas prácticas el nivel mínimo de proteína y el suministro suficiente de aminoácidos azufrados, capaces de satisfacer las demandas de crecimiento y mantener un estado fisiológico normal de la gamitana. 


\section{MATERIALES Y METODOS}

Los estudios fueron realizados en el módulo de nutrición de la Estación Experimental de Pucallpa del Centro de Investigación IVITA de la Universidad Nacional Mayor de San Marcos, teniendo una duración de 150 días.

Se emplearon 12 tanques circulares de fibra de vidrio de 500 litros de capacidad cada uno. La batería de tanques fue abastecida con un flujo continuo de agua doblemente filtrada, proveniente de una represa de 15 hectáreas de espejo de agua.

Los valores de temperatura del agua $(27.0+-0.08$ grado centígrados), oxígeno disuelto(6.70 +- $0.75 \mathrm{mg} / \mathrm{l})$ y $\mathrm{pH}(6.50+-0.08)$, se mantuvieron constantes durante todo el experimento.

Se utilizaron peces saludables y con pesos promedios de 152.70 $+-6.25 \mathrm{~g}$.

Para la elaboración de las dietas experimentales se uttilizaron insumos y subproductos comúnmente disponibles en la región como harina de pescado, torta de soya, maíz amarillo duro, subproducto de trigo y aceite de pescado, Como aditivos se usaron premezcla de vitaminas y minerales, bentonita y BHT(antioxidante).

Las cuatro dietas experimentales (Cuadro 1), se formularon por programación lineal, empleando el programa LP-88. Las dietas fueron isocalóricas $(2700 \mathrm{kcal}$ de energía digestible/ $\mathrm{kg}$ de alimento). Con respecto al contenido de aminoácidos azufrados, se diseñaron en base al requerimiento de metionina + cistina encontrado por Santiago y Lovell(1988) para tilapia del nilo $(0.90 \%$ de la dieta), de tal manera que los porcentajes de metionina + cistina fueron de $0.90,1.02,1.20 \mathrm{y}$ $1.32 \%$ de la dieta. Como fuentes de proteína se utilizaron harina de pescado y torta de soya y como fuentes de energía maíz amarillo duro y subproducto de trigo. El aceite de pescado sirvió para ajustar los niveles de energía requeridos. La energía digestible fue calculada en base a los valores calóricos de Wilson (1977).

Previo al inicio del experimento, los peces fueron acostumbrados al alimento peletizado durante 15 días. Antes del experimento y después de cada muestreo, los peces se sometieron a un baño con una solución de violeta de genciana y oxytetraciclina( $5 \mathrm{ml} / 250$ litros) por 6 horas.

Las cuatro dietas experimentales fueron asignadas al azar por triplicado a 12 tanques circulares de fibra de vidrio, colocándose 4 peces por tanque. La alimentación fue ad-lívitum con una frecuencia de dos veces por día. Los muestreos fueron realizados cada 15 días y se 
evaluaron ganancia de peso, ingesta de alimento, conversión alimenticia, composición de la carcasa (análisis de proteína, lípidos, cenizas y humedad) y proteína retenida. Los datos de composición del cuerpo fueron determinados sobre la base de una muestra total por cada tratamiento y se expresaron en materia seca AOAC (1970).

Para evaluar los efectos de las cuatros dietas se utilizó un diseño estadístico completamente al azar, con tres repeticiones por tratamiento. El análisis de variancia y la prueba de rangos múltiples de Duncan sirvieron para comparar los factores medidos.

\section{RESULTADOS Y DISCUSION}

Los resultados de este estudio (Cuadro 2 ) indican que los juveniles de gamitana obtuvieron su máximo rendimiento $(P<0.01)$ cuando fueron alimentados con la dieta 3 que contenía $25.94 \%$ de proteína, $1.02 \%$ de metionina + cistina y una relación Energía Digestible/Proteína(ED/P) de $10.41 \mathrm{kcal} / \mathrm{g}$ de proteína. Al aplicar la prueba de Duncan, se encontró una ganancia de peso significativamente mejor $(P<0.01)$ con la dieta 3 y una conversión alimenticia (2.72) más baja. El porcentaje de proteína retenida $(72.27 \%)$ por los peces fue significativamente mayor $(P<0.01)$ con la dieta 3 , lo que demuestra un adecuado crecimiento y una eficiente utilización de la dieta.

Las concentraciones óptimas de proteína en las dietas para peces están marcadas por un delicado balance entre proteína y energía, en el que hay que prestar especial atención a la calidad proteica (patrón adecuado de aminoácidos esenciales disponibles) y fuentes de energía no proteica (grasa e hidratos de carbono). Un exceso de energía no proteica, conducirá a una disminución de la ingesta de alimento y por consiguiente a una pérdida de peso. Por otro lado se puede obtener bajos índices de crecimiento o baja rentabilidad económica cuando se utilizan fórmulas con bajo contenido de energía no proteica.

Al analizar nutricionalmente a las dietas observamos que las dietas 1 y 2 tienen bajos niveles de energía no proteica y altos niveles de energía proteica, que se traduce en bajas relaciones ED/P (7.25 y 6.80 $\mathrm{kcal} / \mathrm{g}$ de proteína respectivamente). Metabólicamente el alto contenido proteico ha tenido un destino gluconeogénico y energético, disminuyendo la síntesis de proteína muscular que se expresa bajas ganancias de peso y menor porcentaje de proteína retenida. Por otro lado las dietas 3 y 4 tienen un mejor balance entre la proteína 
y la energía (ED/P de 10.41 y $11.49 \mathrm{kcal} / \mathrm{g}$ de proteína), que significa un mayor destino de la proteína dietaria hacia crecimiento, como lo demuestran las mayores ganancias de peso y mayores porcentajes de proteína retenida conseguidos con estas dietas.

\section{BIBLIOGRAFIA}

AOAC., 1970. Official Methods of Analysis. Washington. D.C. 957 pp.

CARNEIRO,D.J.,1981. Digestibilidade proteica em dietas isocalóricas para o tambaqui, Colossoma macropomum (Cuvier, Pisces). An 2. Simp. Bras. Aquicult. e 2 Enc. Nac. Ranicult., SUDEPE, Brasilia, pp. 788-800.

CEPTA., 1987.Síntesedos trabalhos realizados com especies do género Colossoma. $37 \mathrm{pp}$.

COWEY, C.B. 1974. Protein and aminoacids requirements of finfish. In Finfish nutrition and fishfeed technology. Editado J.E. Halver y K. Tiews. Vol. 1, pp 3-16. Heenemann, Berlin.

DARMONT, M.,J.J. SALAYA. 1984. Ensayo de cultivo de la cachama, Colossoma macropomum, Cuvier 1818, en jaulas flotantes rígidas. Mem. Asoc. Latinoam. Acuicult., 5:465-479.

ECKMANN, R.,1987. Growth and body composition of juvenile Colossoma macropomum, Cuvier(Characoidei) feeding on artificial diets. Aquaculture, 64:293-303.

GUTIERREZ, W.1988. Determinación de los requerimientos de proteína y obtención de la relación óptima energía/proteína en la gamitana (Colossoma macropomum). Informe Técnico. Concytec. 13 pp.

HARDING, D.E.,ALLEN, O.W., WILSON, R.P. 1977. Sulfuramino acids requirements of channel catfish: L-methionine and L-Lysine. J. Nutr. 107, 2031-2035.

KETOLA, H.G.1982. Requirements for dietary lysine and arginine by fry of rainbow trout. Fed. Proc. 42,716. 
KIM, K.I., KAYES,.T.B., AMUNDSON, C.H. 1984. Requirements for sulfur-

containing amino acids by rainbow trout. Fed. Proc. 43, 856.

MACEDO, E.M.1979. Necessidade proteica na nutricao do tambaqui, Colossoma macropomum Cuvier 1818 (Pisces Characidae), M. Sc. Thesis. Univ. Estadual Paulista J abocatibal-Sp. 71 pp.

MEROLA,N.,O.A. CANTELMO. 1987. Grow thfeed conversion and mortality of cage reared tambaqui Colossoma macropomum, fed various dietary feeding regimes and protein levels. Aquaculture, 66:223-233.

MILLIKIN, M.R.1982. Effects of dietary protein concentration on growth, feed efficiency and body composition of age-o striped bass. Trans. Am. Fish.Soc. 111:373-378.

POSTON, H.A., RIIS, R.C., RUMSEY, G.L., KETOLA, H.G. 1977. The effect of suplemental dietary amino acids, minerals and vitamins on salmonids fed cataractogenic diets. Cornell Vet. 67:472-509.

RUMSEY, G.L., PAGE, J.W., SCOTT, M.L. 1983. Methionine and cystine requeriments of rainbow trout. Prog. Fish. Cult. 45:139-143.

SANTIAGO, B.C., R.T. LOVELL. 1988. Aminoacid requeriments for grow th of nile tilapia. American Institute of Nutrition, 1540-1546.

WERDER, U.,U. SAINT-PAUL. 1978. Feeding trials $w$ ith herbivorous and omnivorous amazonian fishes. Aquaculture, 15:175-177.

WILSON, R.P. 1977. Energy relationships in catfish diets. In Nutrition and feeding of channel catfish. Southern Cooperative Series. Bulletin 218:21-25. 


\section{Cuadro 1}

COMPOSICION PORCENTUAL, ANALISIS PROXIMAL Y CONTENIDO DE NUTRIENTES DE LAS DIETAS EXPERIMENTALES PARA GAMITANA (Colossoma macropomum)

\begin{tabular}{|c|c|c|c|c|}
\hline \multirow[t]{2}{*}{ PARAMETROS } & \multicolumn{4}{|c|}{ DIETAS EXPERIMENTALES \% } \\
\hline & 1 & 2 & 3 & 4 \\
\hline \multicolumn{5}{|l|}{ FORMULACION } \\
\hline Maíz & 27.07 & 7.40 & 13.34 & 23.74 \\
\hline S. Trigo & 1.32 & 19.42 & 55.18 & 46.58 \\
\hline H. Pescado & 19.55 & 18.73 & 20.46 & 18.25 \\
\hline T. Soya & 43.31 & 50.95 & 6.68 & 3.12 \\
\hline Aceite & 5.22 & -------- & 0.81 & 4.29 \\
\hline Fosfato & ------ & -------- & ------- & 0.49 \\
\hline \multicolumn{5}{|l|}{ Premezcla } \\
\hline Vit. + Min & 0.50 & 0.50 & 0.50 & 0.50 \\
\hline Bentonita & 3.00 & 3.00 & 3.00 & 3.00 \\
\hline BHT & 0.015 & 0.015 & 0.015 & 0.015 \\
\hline \multirow{2}{*}{\multicolumn{5}{|c|}{$\begin{array}{l}\text { ANALISIS PROXIMAL } \\
\text { (Tal como ofrecido) }\end{array}$}} \\
\hline & & & & \\
\hline $\begin{array}{l}\text { Proteína } \\
\text { Grasa }\end{array}$ & 37.26 & 39.69 & 25.94 & 23.50 \\
\hline Grasa & 6.57 & 2.33 & 4.10 & 9.43 \\
\hline Humedad & 11.80 & 12.60 & 12.90 & 12.60 \\
\hline Ceniza & 5.68 & 8.33 & 6.00 & 9.08 \\
\hline Fibra & 4.50 & 7.50 & 8.17 & 7.17 \\
\hline Nifex & 34.19 & 29.55 & 42.89 & 38.22 \\
\hline \multicolumn{5}{|l|}{ CONTENIDO DE } \\
\hline \multicolumn{5}{|l|}{ NUTRIENTES } \\
\hline Proteína & 37.26 & 39.69 & 25.94 & 23.50 \\
\hline E.D. (kcal/g) & 2.70 & 2.70 & 2.70 & 2.70 \\
\hline $\mathrm{ED} / \mathrm{P}(\mathrm{kcal} / \mathrm{g}$ de & 7.25 & 6.80 & 10.41 & 11.49 \\
\hline Lisina (\% de la dieta) & 2.30 & 2.57 & 1.65 & 1.40 \\
\hline Metionina (\% de la & 0.72 & 0.76 & 0.61 & 0.54 \\
\hline \multicolumn{5}{|l|}{ Metionina + Cistina } \\
\hline Calcio & 0.90 & 0.90 & 0.90 & 0.90 \\
\hline Fósforo disponible & 0.59 & 0.61 & 0.60 & 0.59 \\
\hline
\end{tabular}




\section{Cuadro 2}

EFECTO DE LOS NIVELES DE METIONINA + CISTINAEN LA DIETA SOBRE EL CRECIMIENTO Y RETENCION DE PROTEINA EN GAMITANA (Colossoma macropomum)

\begin{tabular}{|c|c|c|c|c|}
\hline \multirow[t]{2}{*}{ PARAMETRO } & \multicolumn{4}{|c|}{ DIETAS EXPERIMENTALES } \\
\hline & 1 & 2 & 3 & 4 \\
\hline \multicolumn{5}{|l|}{ Peso inicial (g/pez) } \\
\hline & $\begin{array}{l}148.30 \\
+-5.2\end{array}$ & $\begin{array}{l}165.80 \\
+-8.0\end{array}$ & $\begin{array}{l}152.50 \\
+-6.6\end{array}$ & $\begin{array}{l}144.20 \\
+-5.2\end{array}$ \\
\hline \multicolumn{5}{|l|}{ Peso final (g/pez) } \\
\hline & $\begin{array}{l}206.70 \\
+-4.4\end{array}$ & $\begin{array}{l}219.20 \\
+-8.5\end{array}$ & $\begin{array}{l}228.90 \\
+-3.6\end{array}$ & $\begin{array}{l}189.90 \\
+-6.0\end{array}$ \\
\hline \multicolumn{5}{|l|}{ Ganancia total (g/pez) } \\
\hline Crecimiento & $58.40 a$ & $53.40 a$ & $76.40 \mathrm{~b}$ & $45.70 a$ \\
\hline $\begin{array}{l}\text { (g/día/pez) } \\
\text { Conversión alimenticia }\end{array}$ & 0.39 & 0.36 & 0.51 & 0.30 \\
\hline \multirow{2}{*}{ Proteína retenida (\%) } & 3.55 & 3.90 & 2.72 & 4.61 \\
\hline & $49.55 a$ & $43.18 a$ & $72.27 b$ & $55.65 a$ \\
\hline
\end{tabular}

Los valores promedios seguidos por la misma letra no son significativamente diferentes $(P<0.01)$ por la Prueba de Duncan. 